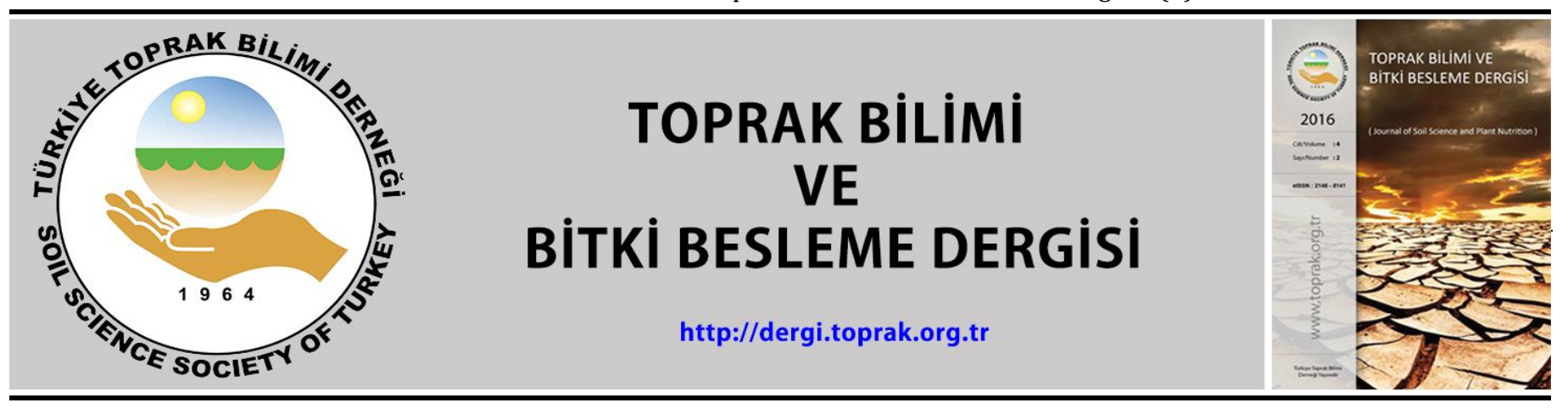

\title{
Toprağa karıştırılan pirina kompostu ve arıtma çamurunun mikrobiyal popülasyona ve solucan (Eisenia fetida l.) davranışlarına etkisi \#
}

\section{Cafer Türkmen*, Remzi İlay, Nuri Burak Aslantekin, Yasemin Kavdir}

Çanakkale Onsekiz Mart Üniversitesi, Ziraat Fakültesi, Toprak Bilimi ve Bitki Besleme Bölümü, 17020 Çanakkale

\begin{abstract}
Özet
Günümüzde tarımsal ürünler ve kentleşmenin artmasıyla tarımsal sanayi ve kentsel atıklar giderek artmıştır. Bu durum, atıkların bertaraf edilmesi ve farklı amaçlarla yeniden değerlendirilmesi konularına yönelik bilimsel çalıșmaları gerektirmiștir. Çanakkale'de zeytinyağı üretimi sonrası açığa çıkan Pirinadan (P) elde edilen kompost ile ileri biyolojik atıksu arıtma tesislerinde üretilen Arıtma Çamurunun (AÇ) materyal olarak kullanıldığı bu çalışmada materyaller toprağa ağırlıkça \%0, \%1 ve \%3 seviyelerinde karıștırılmıștır. Karıșımlar iki boyutlu (2D) şeffaf cam düzeneklere alınmış, tarla kapasitesine kadar nemlendirilen düzeneklere üçer adet solucan (Eisenia fetida L.) bırakılmış ve düzenekler üç gün $18{ }^{\circ} \mathrm{C}$ 'de inkübe edilmiştir. İnkübasyon sonrası 2D düzeneklerindeki solucan hareketlerine bağlı galeri alanları (GA-mm²) ve mikroorganizma sayıları (MOS) belirlenmiştir. Elde edilen verilere göre, \% 0 (kontrol) grubunda 2D düzeneğin her iki tarafındaki GA ve MOS arasındaki farkların istatistik bakımdan önemli olmadığı anlaşılmıştır $(\mathrm{p}>0,05)$. Bir tarafında kontrol diğer tarafında karışımların olduğu düzeneklerden; \%1 AÇ, \%1 P ve \%3 P olan topraklarda GA aralarındaki farkların olduğu $(\mathrm{p}<0,05)$, ancak MOS değerleri bakımından uygulamaların hiçbirinde önemli fark olmadığı $(p>0,05)$ anlaşılmıştır. Solucanların toprağa karıştırılan farklı organik materyallere yönelimlerinin farklı olduğu galeri alanlarındaki farklardan anlaşılmış, ancak uygulama yapılan tüm topraklarda MOS sayılarındaki değişimin önemsiz olduğu tespit edilmiștir.
\end{abstract}

Anahtar Kelimeler: Arıtma çamuru, pirina, kompost, solucan, mikroorganizma, toprak.

\section{Microbial population and earthworm behavior (Eisenia fetida L.) in olive pomace compost and sewage sludge applied soil}

\begin{abstract}
Today, with the increase of agricultural products and urbanization, agricultural industry and urban wastes are increasing. This situation necessiated new scientific studies on the waste disposal and evaluation of wastes for different purposes. Olive pomace (P) compost and sludge (AC) from wastewater treatment plants mixed with soil at the rates of $0 \%, 1 \%$ and $3 \% \mathrm{w} / \mathrm{w}$. Mixtures were filled up into 2-dimensional (2-D) clear glass assemblies (terrarium) and water was added to maintain the moisture level at the field capacity. Each treatment received three earthworms (Eisenia feotida L.) and the terrariums were placed in the incubator for three days at $18{ }^{\circ} \mathrm{C}$. Gallery areas resulted from earthworm movements (GA- $\mathrm{mm}^{2}$ ) and microorganism numbers (MOS) were determined after the incubation. According to the results, no significant difference was found between the GA and MOS values on both sides of the $2 \mathrm{D}$ glass plate in the $0 \%$ (control) group ( $p>0.05)$. GA values were found to be significant $(p<0.05)$ in the soil with $1 \% \mathrm{AC}, 1 \% \mathrm{P}$ and 3\% P compared to control treatment. On the other hand MOS numbers were not statistically significant ( $\mathrm{p}>0.05)$. Worms have different orientations towards different organic materials mixed into the soil which effected on gallery areas. However it has been found that the change in MOS numbers was not significant in all soils.

Keywords: Sewage sludge, olive pomace, compost, earthworm, microorganism, soil.
\end{abstract}

(C) 2019 Türkiye Toprak Bilimi Derneği. Her Hakkı Saklıdır

\section{Giriş}

Son yüzyılda artan dünya nüfusunun gıda ihtiyacı tarımsal ürünlerin artırılmasını gerektirmiș bu sebeple "birim alandan daha yüksek verim alma" amacı ile topraklarımız bozunmaya başlamıștır. Ülkemizde de

\footnotetext{
* Sorumlu yazar:

\# Bu makale "II. Çanakkale Tarımı Sempozyumu"nda (14-15 Aralık 2017 Ziraat Fakültesi/Çanakkale) poster bildiri olarak sunulmuş olup, sempozyum bildiri özetleri kitapçı̆ında benzer özeti basılmıștır.

Tel.

E-posta

02862180018

turkmen@comu.edu.tr

Gelis Tarihi

Kabul Tarihi

23 Eylül 2019

13 Aralık 2019

e-ISSN : $2146-8141$

DOI : $10.33409 /$ tbbbd.668632
} 
giderek artan nüfus ve kentleșme sonucu, bașta tarımsal üretime dayalı organik atıklar olmak üzere kentsel katı atıklarda da önemli artışlar olmuştur (Anonim, 2016a).

Atık yönetimi ile ilgili Avrupa Birliği uyum yasaları gereği olarak ülkemizde belediyelere önemli görev ve yükümlülükler yüklenmiştir. Bu kapsamda kentlerde katı atıkların düzenli depolanması ve atık suların arıtılmaları için arıtma tesisleri kurulmaları sağlanmıștır. Bu atık su arıtma tesislerinden elde edilen arıtma çamurları için Bruce ve Davis (1988), "tüm geleneksel atık su arıtma işlemlerinin kaçınılmaz son ürünüdür" ifadesini kullanmışlardır.

Ülkemizde organik kökenli evsel katı atıklar ve atık su arıtma tesislerinden elde edilen arıtma çamurları, organik atıklar içerisinde önemli miktarları oluşturmaktadır. Çevre Bakanlığı'mızca "tehlikeli katı atıklar" sınıfında görülen arıtma çamurlarının önemli bir kısmı bilinçli veya bilinçsiz olarak tarım alanlarında kullanılarak bertaraf edilmeye çalışılmaktadır (Arcak ve ark., 2000)

Türkiye İstatistik Kurumu'nun yapmış olduğu belediye atık su istatistikleri anketine göre, kanalizasyonlarla 4,5 milyar $\mathrm{m}^{3}$ atık su gelmekte ve bunun 3,8 milyar $\mathrm{m}^{3}$ 'ü atık su arıtma tesislerinde arıtılmaktadır. Arıtıldıktan sonra organik kısmı ayrılan atık suyun \%44,9'u denizlere, \%45'i akarsulara, \%2'si barajlara, \%1,4'ü göl/göletlere, \%0,4'ü araziye ve \%6,3'ü diğer alıcı ortamlara aktarılmakta ve yılda 299.000 ton kuru arıtma çamuru oluşmaktadır (Anonim, 2016a).

Arıtma çamurları; kurutularak fabrikalarda yakıt olarak tüketilmekte, tarım alanlarında toprak düzenleyici olarak yönetmeliklerin izin verdiği sınırlı miktarlarda kullanılmakta ve tehlikesiz görülenler katı atık düzenli depolama alanlarında depolanmaktadır. Ancak yine de binlerce ton arıtma çamurunun nerede ve nasıl bertaraf edileceği sorusu ülkemizde de sıklıkla gündeme gelmektedir.

Önemli tarımsal ürünlerimizden zeytin ve zeytinyağı üretimi özellikle İspanya, İtalya, Yunanistan, Suriye, Türkiye ve Tunus gibi Akdeniz ülkelerinde önemli bir sosyo-ekonomik rol oynamaktadır. Dünya zeytinyağı üretiminin \%98'i Akdeniz ülkeleri tarafından yapılmaktadır (IOOC, 2011). Zeytinyağı üretiminde genellikle 3 yöntem kullanılmakta olup seçilen üretim metoduna göre atık miktarlarının oranları arasında farklıklar bulunabilmektedir (İlay, 2009). Türkiye'de zeytinyağı üretimi sonucunda açığa çıkan katı atığa "pirina" denilmektedir. Zeytinyağı üretimi için kullanılan 1 ton zeytinden, geleneksel yöntemde $400 \mathrm{~kg}, 2$ fazlı sistemde 800-950 kg ve üç fazlı sistemlerde ise 500-600 kg pirina açığa çıkmakta olup, ülkemizde ortalama yıllık 268000 ton pirina elde edilmektedir (İlay, 2009). Üretim sistemlerine bağlı olarak farklı oranlarda ortaya çıkan yan ürünlerin miktarlarının fazla olması, bertarafının zor olması ve depolanma sorunları nedeniyle ciddi çevresel problemlere yol açmaktadır (Niaounakis ve Halvadakis, 2004; Azbar ve ark., 2004; İlay, 2009; İlay ve ark., 2013).

Roig ve ark. (2006), yaptıkları çalışmada, iki fazlı ve üç fazlı zeytinyağı üretim atıklarını farklı metotlarla değerlendirmişler ve önerilen metotlar içinde en uygun yöntemin kompostlaştırma işlemi olduğunu, bu yöntemin diğer yöntemlere göre daha pratik olduğunu, ekonomik değerinin yüksek olduğunu ve organik tarımda çok önemli rol oynayabileceğini belirtmişlerdir.

Kavdir ve Killi (2008), yaptıkları çalışmada pirinanın belli bir orana kadar toprağa direk uygulanabileceğini fakat hayvan gübreleri ile beraber kompostlaştırılması ile atıkların değerinin artacağını bildirmişlerdir.

Topraklara çeşitli doğal organik materyallerin veya kompostlanmış organik maddelerin uygulanması tarımsal ürünlerde verim artışları yanında, toprak ıslahı amacıyla da kullanılmaktadır (Öztürk ve ark., 2010; Özdemir ve Durmuş, 2016). Organik maddeler toprakta agregatlaşmayl artırarak toprak pH stabilizasyonunu ve infiltrasyon hızını artırır (Özdemir ve Durmuş, 2016). Toprak organik madde kapsamı, pH ve EC gibi toprağın kimyasal özelliklerini ve dolayısıyla topraktaki mikroorganizma faaliyetini etkileyerek enzim aktivasyonunda da bazı önemli değişiklikler meydana getirmektedir (Sofi ve ark., 2016; Zhongjun ve ark., 2017)

Baker ve ark. (2003), toprakta besin maddesi döngülerinde solucanların fiziksel ve biyokimyasal etkilerinin çok önemli olduğunu, bu durumun ekosistemdeki tüketiciler ve ayrıştırıcıların toprağa bağlılığını artırdığını belirtmişlerdir.

Ekosistemlerin devamlılı̆̆ı için canlılarda biyoçeşitlilik çok gereklidir. İnsanların hayatı bu faktörlere bağımlıdır. Ekosistemler içinde "devamlı doğurganlık" önemli bir kavram olmaya başlamıştır ve bu kavram toprak organizmaları ile sıç̧a anılır olmuştur (Lee, 1985; Busby ve ark., 2017). Günümüzde artık sürdürülebilir tarım, ekosistem ve insan sağlığı için toprağın ruhundan ve çevre ahlakından bahsedilmeye başlanmıştır (Thompson, 2017). 
Solucanlar, topraklardaki canlı biokütlenin en önemli üyelerinden olup "ekosistem mühendisleri" olarak adlandırılırlar (Blouin ve ark., 2013). Solucanlar topraktaki bitki atıklarını tüketip sonrasında toprakla birleştirilmiş olarak tekrar boşaltmak suretiyle toprak agregatlarının oluşumuna ve dayanıklılığına katkıda bulunur ve şekilde bitki gelişimi için toprak fiziksel şartlarının iyileştirilmesinde önemli rol oynarlar (Kavdir ve İlay, 2011). Solucanlar toprakta su geçirgenliğini ve poroziteyi artırmaktadırlar. Bu yönleriyle solucanlar tarım alanlarında yüzeye uygulanan organik materyallerin, kirecin ve gübrelerin toprağa karışımını sağlarlar ve bu karışım sürecini hızlandırırlar. Bitki kök gelişimine önemli katkıları ile kök hastalıklarını önemli miktarda düşürürler (Anonim, 2017).

Lumbricus terrestris cinsi solucanlar önemli bir kirlilik indikatörü olarak kabul edilmektedir (Anonim, 2017). $\mathrm{Bu}$ tür solucanların özellikle kirlilik unsurlarını biyoakümülasyonu nedeniyle kuşlara ve diğer solucanla beslenen kara canlılarına taşınmasındaki potansiyelleri yüksek olmaktadır. Bu potansiyele dikkat çekilen toprak solucanlarının iyi bilinen örneklerinden olan Lumbricus ailesinin dünyada 500 ten fazla türü olup ülkemizde 75 kadarı tespit edilmiștir, ancak ülkemizde L. terrestris cinsine ait 2014 yllı itibariyle bir tür kaydı olmadığı da belirtilmektedir (Mısırlıŏlu, 2014).

Topraklara kompost ve organik madde katmak, besin maddelerinin uzun süre tutulmalarını ve yavaş salınımlarını sağlayarak ürün verimi arttırır. Ayni zamanda toprak mikrobiyal biokütlesini arttırır ve toprakların fiziksel özelliklerini geliştirir (Bertan ve ark., 2003; Öztürk ve ark., 2010). Dominguez ve Edwards (2011), benzer olarak bitkinin toprakta yer alan mikro ve makro besin elementlerini daya iyi ve uzun sürede kullanması amacına yönelik olarak vermikompost'un bitkilerin istediği zamanda ve formda alabilecekleri besin maddeleri içerdiğini ve yavaş salınımlı olduğunu belirtmiş̧lerdir.

Solucanların taze organik materyallerce zengin, nemli ve sıcak yerlerde fazlaca bulunduğu eskiden beri bilinmektedir (Evans, 1947; Fuller, 1954). Son yıllarda solucanların toprak kalitesini belirleme yönüyle biyolojik indikatör olarak ele alınma düşüncesi, bilim adamlarını bu yöndeki araştırmalara (Evans, 1947; Graff, 1953; Fuller, 1954; Dunger, 1983; Paoletti ve ark.,1998; Fründ ve ark., 2009; Lowe ve ark., 2016; Dawood ve ark., 2017) yönelten önemli bir gelişme olmuştur.

Yapılan bir başka çalışmada; solucanların açtıkları galeri alanlarının bilinmesinin topraklarda bu canlıların ekolojik olarak yönelimlerinin belirlenmesinde ve bu işlem için kullanılan 2D sisteminin, pahalı cihazdonanım gerektiren yöntemlere göre daha ekonomik ve ekolojik bir yöntem olabileceği bu nedenle 2D yöntemi seçilerek solucanlarla ilgili ekolojik çalışmaların yaygınlaştırılması ve farklı bakış açılarıyla sorgulanması gerektiği belirtilmiștir (Türkmen ve ark., 2013; 2018).

Toprak kalitesi kriterlerini belirleme çalışmaları içinde önemli fiziksel, kimyasal ve biyolojik toprak özellikleri sayılmaktadır. Bunlar içinden azot mineralizasyonu, mikrobiyal biyomas, toprak solunumu ve toprak solucanları önemli biyolojik parametreler olarak ifade edilmektedir. Benzer şekilde çok sayıda fiziksel ve kimyasal toprak kalite kriterlerinin de sıklıkla incelen özelliklerden olduğu bildirilmektedir (Karlen ve ark., 2003; Gülser ve Kızılkaya, 2013; Bünemann ve ark., 2018). Bunlardan sadece toprak kimyasal kalite ölçütleri kapsamındaki bir özellik olan ağır metallerin incelenmesi için bile Atomik Absorbsiyon Spektrofotometresi gibi pahalı cihazlar ve donanımlar gerekmektedir. Biyolojik kalite ölçütlerinden olan solucanların sayıları, türleri ve doğal ortamlarındaki hareketlerinin belirlenmesi de oldukça zor, pahalı ve uzmanlık gerektiren yöntemlerdendir. Ancak materyal ve metot kısmında detayları açıklanan 2D düzeneği sistemi ile solucan yönelimlerinin ölçülmesini temel alan kolay ve masrafsız bir yöntemle çalışmalar yaparak halen biyolojik indikatör olarak ele alınan solucanlar ek olarak; kaliteli toprakların teșhisinde, topraklara karıştırılacak organik/inorganik materyallerin solucanlara etkilerinin öngörülmesinde ve hatta diğer toprak kalite parametreleriyle solucan yönelimlerinin korelasyonlarının yapılması gibi birçok yararlı çalışmalara kapı açılabileceği düşünülmektedir.

Bu çalışma, Eisenia fetida türü toprak solucanı kullanarak topraklara karıştırılan iki farklı organik atık olan arıtma çamuru ve pirina kompostunun solucanların yönelimlerine etkilerini belirlemek için yapılmıștır. Daha önce Ankara kenti atıksularından elde edilen arıtma çamurunu solucanlara yedirerek vermikompost üretimi sağlanmış (Kızılkaya ve ark., 2012), ancak Çanakkale kenti atıksularından elde edilen arıtma çamuru ve Çanakkale yöresi zeytinlerinin işlenmesi sonucu elde edilen pirinanın solucan yönelimlerine etkilerinin 2D düzeneği kullanılarak incelendiği ilk çalışma olmuştur.

\section{Materyal ve Yöntem}

Bu çalışmada kullanılan solucanlar, son yıllarda piyasada çok rastlanan ve vermikompost yapımında en etkin türlerden biri olan Eisenia fetida olmuştur. Çalışmada Çanakkale Belediyesi İleri Biyolojik Atıksu Arıtma 
Tesisi'nden temsilen alınan arıtma çamuru kurutulup homojenize edildikten sonra 4 mm'lik elekten geçirilerek kullanılmıştır. Pirina ise Gökçeada (Çanakkale)'da bulunan Elta Tarım İşletmesi'nden elde edilmiş ve ahır gübresi ile karıștırılarak kompostlaștırılmıș, kurutulmuș daha sonra $4 \mathrm{~mm}$ 'lik elekten elenerek homojen hale getirilen kısımdan alınarak kullanılmıştır. Çizelge 1'de kullanılan materyallerin ve toprağın temel özellikleri ve bazı besin elementleri verilmiştir. Denemede 2D sistem için gerekli toprak ise ÇOMÜ Ziraat Fakültesi Dardanos Yerleşkesi'ndeki tarla denemeleri için ayrılan parsellerden alınmış, kurutulup ezildikten sonra 2 mm'lik elekten geçirilerek kullanılmıştır.

Çizelge 1. Denemede kullanılan materyallerin bazı özellikleri ve toplam element içerikleri*

\begin{tabular}{lccc}
\hline İncelenen Özellikler & Pirina Kompostu & Aritma Çamuru & Toprak \\
\hline Organik madde (\%) & 61,57 & 42,73 & 1,81 \\
pH & 7,90 & 6,39 & 8,01 \\
$\mathrm{EC}\left(\mu \mathrm{S} \mathrm{cm}^{-1}\right)$ & 299 & 420 & 639 \\
$\mathrm{~N}(\%)$ & 1,98 & 4,36 & 0,070 \\
$\mathrm{P}(\%)$ & 0,04 & 1,92 & 0,093 \\
$\mathrm{~K}(\%)$ & 0,57 & 0,173 & 0,165 \\
$\mathrm{Fe}(\mathrm{ppm})$ & 1881 & 1261 & 2341 \\
$\mathrm{Cu}(\mathrm{ppm})$ & 10,05 & 127,78 & 8,96 \\
$\mathrm{Mn}(\mathrm{ppm})$ & 189 & 260,69 & 0,33 \\
$\mathrm{Zn}(\mathrm{ppm})$ & 53 & 785,85 & 42,44 \\
$\mathrm{CaCO}(\%)$ & ------ & ---- & 11,86 \\
Bünye & ----- & ----- & Tin $(\% 51 \mathrm{Kum}, \% 35$ Silt, \%14 Kil) \\
\hline
\end{tabular}

*: Veriler; İlay ve ark. (2013), Kavdır ve ark. (2010) ve T.C. Gıda Tarım ve Hayvancılık Bakanlı̆̆ı, Toprak-Gübre ve Su Kaynakları Merkez Araştırma Enstitü Müdürlüğü Analiz Raporu (Anonim, 2016b) ile Bölümümüz laboratuvarlarında yapılan analiz verilerinden alınmıștır/üretilmiştir. Analizler ise; Kacar ve Kütük (2010), EPA-3052 (1996) ve Müftüoğlu ve ark. (2014)'e göre yapılmıştır.

Denemede kullanılan 2D terrarium düzeneği (Evans, 1947), A4 kâğıt ebatlarına göre kesilmiş camlardan hazırlanmıștır. Kesilen camların her iki tarafından arasına 4'er mm'lik ahşap çıta, camların alt tarafına ise toprağın dökülmemesi için temiz bir bez konularak oluşturulmuş ve dört köşesinden birer kıskaç ile sıkıștırılmıștır (Dunger, 1983; Leibner ve ark., 2008; Fründ ve ark., 2009; Fründ ve ark., 2011). Hazırlanan bu düzeneklerin tam ortasından iki cam arasına girecek uygun bir çubuk yardımıyla düzenekler iki bölmeye ayrılmıştır. Tüm düzeneklerin ayrılan bir bölüme $2 \mathrm{~mm}$ 'den elenmiş 100'er gram kontrol toprağı, diğer kısmına ise belirli oranlarda (\%0, \%1, \%3) organik materyal katılan 100'er gram topraklar konulmuştur (Şekil 1).
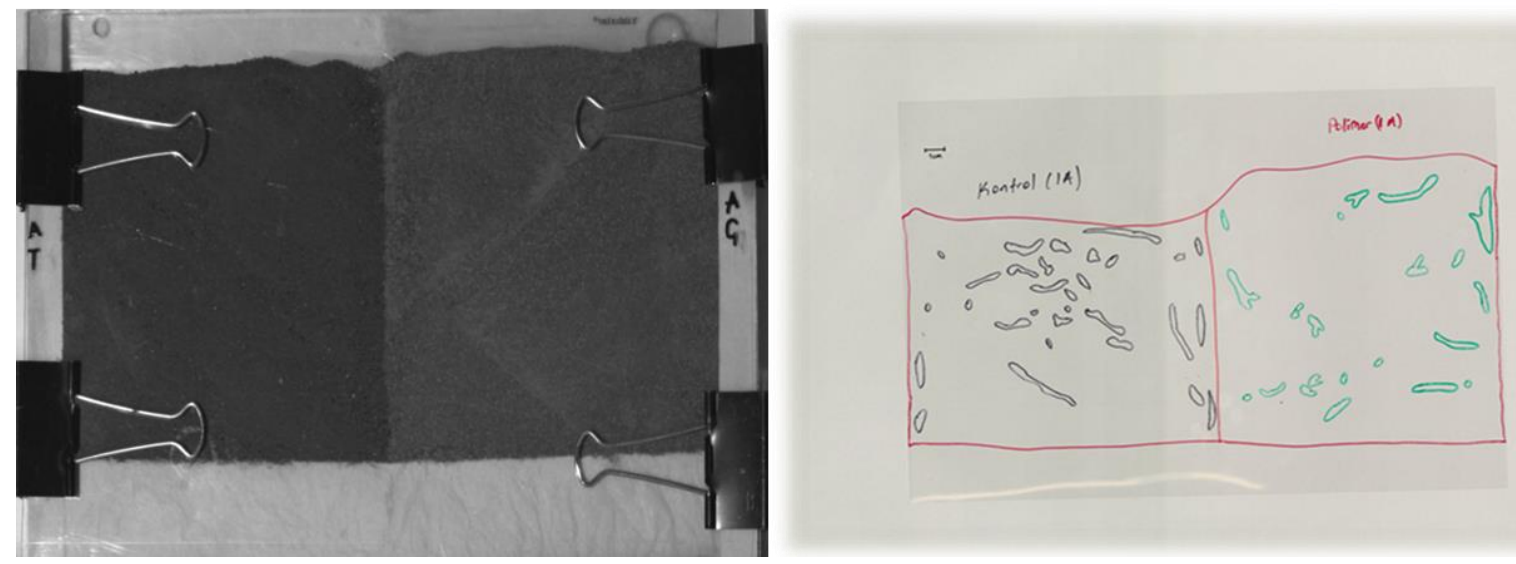

Şekil 1. 2D düzeneğinin görüntüsü ve asetat üzerine galeri alanlarının alınması (orijinal fotoğraftır).

Üçer tekrarlı olarak 2D sistemlere yerleştirilen karışımlar tarla kapasitesine kadar nemlendirildikten sonra düzeneklerin her birinin ortasından eșit ağırlıkta üçer solucan yerleştirilmiştir. Bu işlemler her iki organik atık için tekrar edilmiştir. Oluşturulan 2D cam düzenekler su dolu küvetlere yerleştirilmiş ve toprağın tarla kapasitesine kadar doygun hale gelmesi sağlanmıștır. Hazır hale gelen düzeneklerdeki camlar arasındaki toprak üzerine düzeneğin tam ortasından ortalama ağırlıkları eşit olacak şekilde 3'er solucan bırakılmıştır.

Solucanlar sisteme yerleştirildikten sonra siyah bir bant yardımı ile açık kalan üst kısımlar kapatılmış ve havalanması için bant üzerine küçük delikler açılmıştır. Tüm düzenekler hazırlandıktan sonra solucanlar karanlıkta ve $+18^{\circ} \mathrm{C}$ 'ye ayarlanmış inkübatörde üç gün bekletilmiştir. Bu süre sonunda laboratuvar ortamına alınan solucanların açtığı galerileri asetat kâğıdı üzerine renkli ince uçlu asetat kalemleri yardımıyla 
çizilmiştir. Asetatlara alınan alanlar kapalı ve taralı hale getirildikten sonra solucanların açtığı tünel alanları WinRHIZO Basic Pro-2007 kök programı yardımıyla (WinRHIZO Basic Pro-2007, Regent Instruments Inc., Quebec) $1 \mathrm{~cm}^{2}$ referans okuması yapılarak ölçülmüștür (Gallagher ve ark., 2015).

İstatistik analizlerde; kontrol grubu ile diğer gruplar arasındaki galeri alanları bakımından MINITAB 16.0 paket programı ile varyans analizine tabi tutulmuş (ANOVA) ve gruplar arasındaki farklılıkları LSD testi ile ortaya konulmuştur.

\section{Bulgular ve Tartışma}

Araştırma sonucu elde edilen verilere göre, hiçbir uygulama yapılmayan kontrol grubunda 2D düzeneğin her iki tarafındaki GA ve MOS değerleri arasındaki farkların önemli olmadığı tespit edilmiştir ( $p>0,05)$. Bir tarafında kontrol diğer tarafında karışımların olduğu düzeneklerden; \%1 AÇ, \%1 P ve \%3 P olan topraklarda GA değerleri arasındaki farkların istatistiksel olarak önemli olduğu (Şekil; 2,3,4), ancak MOS değerleri dikkate alındığında uygulamaların arasında önemli fark olmadığı ( $>00,05$ ) anlaşılmıştır (Çizelge 2). Solucan galerilerinin büyük kısmı \%1 pirina kompostu ilave edilen 2D terrariyumda (düzenekte) oluşmuştur, bu da organik açıdan zengin toprak için solucanın net bir tercihi olduğunu göstermektedir. Benzer sonuçlar Felten ve Emerling (2009), Türkmen ve ark. (2013) ve Türkmen ve ark. (2018) tarafından farklı atıklar ve solucan türleri için bildirilmiştir.

Solucanların toprağa karıştırılan farklı organik materyallere yönelimlerinin farklı olduğu galeri alanlarındaki farklardan anlaşıılmış, ancak uygulama yapılan tüm topraklarda MOS sayılarındaki değişimin önemsiz olduğu tespit edilmiştir (Çizelge 2). Solucanlar bazen kirletici maddeleri hissedebilirler ve genellikle kirli topraklardan kaçınma eğilimindedirler (Stephenson ve ark., 1998). Bu nedenle solucanların pirina kompostuna yönelmesi, bu kompostun zararlı olmadığının veya solucanlar için itici bir madde olmadığının göstergesi olabilir.

Çizelge 2. Çamur ve pirina uygulamalarının galeri alanı ve mikroorganizma sayılarına etkileri.

\begin{tabular}{|c|c|c|c|c|c|c|}
\hline & \multicolumn{3}{|c|}{ Galeri alanı $\left(\mathrm{mm}^{2}\right)$} & \multicolumn{3}{|c|}{ Mikroorg. Sayısı (Adet/g Toprak) } \\
\hline & Toprak & Uygulama & P değeri & Toprak & Uygulama & P değeri \\
\hline Kontrol & 1386 & 1380 & 0,976 & $3,38 \times 10^{6}$ & $3,40 \times 10^{6}$ & 0,972 \\
\hline \%1 Çamur & $1128 \mathrm{~B}$ & $1486 \mathrm{~A}^{*}$ & 0,008 & $4,16 \times 10^{6}$ & $7,06 \times 10^{6}$ & 0,199 \\
\hline \%3 Çamur & 1067 & 1416 & 0,093 & $5,77 \times 10^{6}$ & $5,91 \times 10^{6}$ & 0,947 \\
\hline \%1 Pirina kompostu & $1722 \mathrm{~B}$ & $2307 \mathrm{~A}$ & 0,018 & $5,05 \times 10^{6}$ & $3,56 \times 10^{6}$ & 0,286 \\
\hline \%3 Pirina kompostu & $1222 \mathrm{~B}$ & $1911 \mathrm{~A}$ & 0,005 & $3,88 \times 10^{6}$ & $4,75 \times 10^{6}$ & 0,651 \\
\hline
\end{tabular}

*:Aynı satırdaki farklı harfler, uygulamalar arasındaki istatistiksel farkı belirtmektedir $(\mathrm{p}<0,05)$.

Çizelge 2'ye göre E. fetida türünün uygulama alanları içerisinde, toprağa \%1 oranında karıştırılan pirina kompostunda en çok galeri alanı $\left(2307 \mathrm{~mm}^{2}\right)$ oluştururken, toprağa \%3 oranında karıştırılan çamur ise en az galeri alanı $\left(1416 \mathrm{~mm}^{2}\right)$ oluşturduğu görülmektedir.

Çizelge 2'ye göre E. fetida türünün uygulama alanları içerisinde, toprağa \%1 oranında karıștırılan çamur ile en çok mikroorganizma sayısı $\left(7,06 \times 10^{6}\right)$ olurken, toprağa \%1 oranında karıştırılan pirina kompostu ile en az mikroorganizma sayısı $\left(3,56 \times 10^{6}\right)$ oluştuğu görülmektedir.

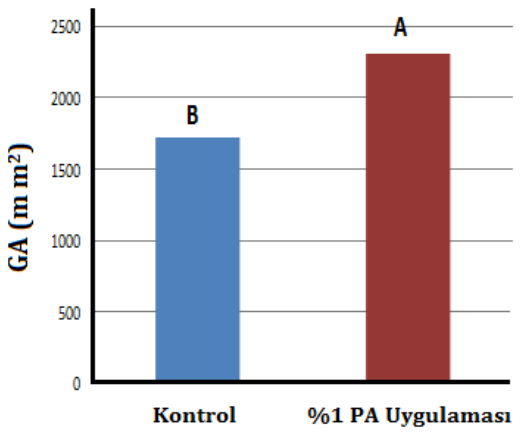

Şekil 2. Eisenia fetida solucanlarının kontrol (katkısız toprak) ile \%1 pirina kompostu uygulanan topraktaki galeri alanları $\left(\mathrm{mm}^{2}\right)$.

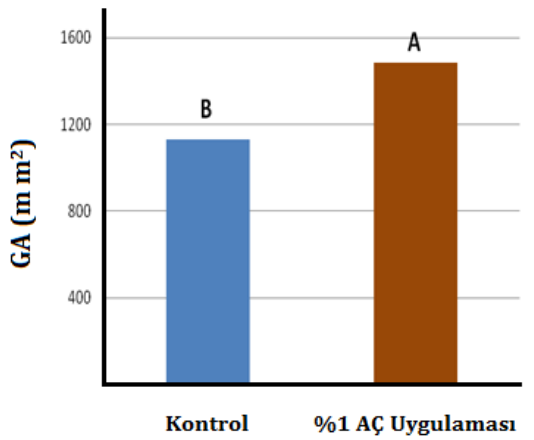

Şekil 3. Eisenia fetida solucanlarının kontrol (katkısız toprak) ile \%1 atık çamur uygulanan topraktaki galeri alanları $\left(\mathrm{mm}^{2}\right)$.

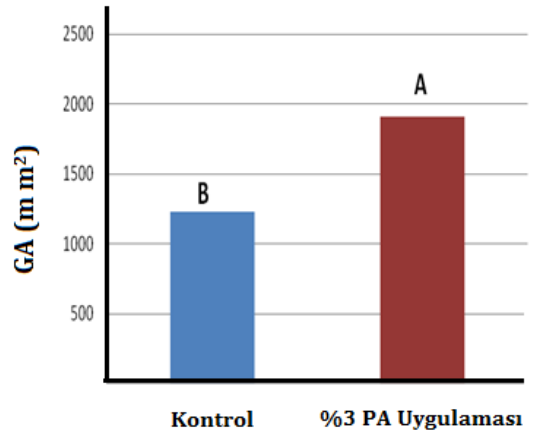

Şekil 4. Eisenia fetida solucanlarının kontrol (katkısız toprak) ile \%3 pirina kompostu uygulanan topraktaki galeri alanları $\left(\mathrm{mm}^{2}\right)$. 


\section{Sonuç}

$\mathrm{Bu}$ araştırmada solucanların toprağa karıştırılan farklı organik materyallere göre yönelimlerinin de farklı olduğu galeri alanlarındaki uygulama seviyelerine bağlı olarak değișen farklardan anlaşılmış olup, uygulama yapılan tüm topraklardaki MOS sayılarındaki değişimin önemsiz olduğu tespit edilmiştir. Mikroorganizma sayılarındaki değişimlerin sayısal olarak farklı olmasına rağmen (Çizelge 2) bu farkların önemsizliği; 2D sistemler içindeki solucanların haraketli olması nedeniyle fazla tekerrürle çalışma şansının az olmasına ve toprağa katılan organik materyallerin her ikisinin de üç günlük deneme süresi içinde ayrışıp parçalanmasının mümkün olmaması nedenine dayandırılabilir.

$\mathrm{Bu}$ çalışma kapsamında elde edilen verilere göre; solucanların temel ekosistemleri olan toprak ortamına katılan organik materyallere verdiği tepkilerin ölçülebilir olduğu anlaşılmıştır. Son yıllarda sürdürülebilir tarım ve çevre kavramları kapsamında giderek önemi artan toprağın kalitesi, kirliliği ve verimliliği çalışmalarında solucanların bu tür tepkilerinin gösterge olarak kullanılabileceği düşünülmelidir. Kısa zamanda 2D sistemin ve solucanların kullanıldığı bu metotla toprak özellikleri ve kalitesi hakkında fikirler elde edilebilir, bu metot daha da geliştirilebilir ve diğer toprak özelliklerine ve canlılarına etki edebilecek katkı maddeleriyle yeni çalışmalar kurgulanabilir.

\section{Kaynaklar}

Anonim, 2016a. TÜIK (Türkiye İstatistik Kurumu), Belediye Atıksu İstatistikleri Haber Bülteni, Sayı: 24875.

Anonim, 2016b. T.C. Gıda Tarım ve Hayvancılık Bakanlığı, Toprak-Gübre ve Su Kaynakları Merkez Araştırma Enstitü Müdürlüğü Analiz Raporu, Yenimahalle/Ankara.

Anonim, 2017. http://www.bugday.org/portal/haber_detay.php?hid=150 (Erişim tarihi; 24.12.2017).

Arcak S, Türkmen C, Karaca A, Erdoğan E, 2000. A Study on potential ağricultural use of sewage sludge of Ankara wastewater treatment plant. Proceeding of International Symposium on Desertification, 13-17, Konya.

Azbar N, Bayram A, Filibeli A, Muezzinoglu A, Sengul F, Ozer A, 2004. A review of waste management options in olive oil production. Critical Reviews in Environmental Science and Technology, 34(3), pp.209-247.

Baker GH, Amato M, Ladd J, 2003. Influences of Aporrectodea trapezoides and A. rosea (Lumbricidae) on the uptake of nitrogen and yield of oats (Avena fatua) and lupins (Lupinus angustifolius). Pedobiologia. 47: 857-862.

Bertan E, Sort X, Soliva M, Trillas I, 2003. Composting winery waste: Sludge and grape talks, 3 July, Barcelona-Spain.

Blouin M, Hodson ME, Delgado EA, Baker G, Brussaard L, Butt KR, Dai J, Dendooven L, Peres G, Tondoh JE, Cluzeau D, Brun JJ, 2013. A review of earthworm impact on soil function and ecosystem services. European Journal of Soil Science. 64: 161-182.

Bruce AM, Davis RD, 1988. Sewage Sludge Disposal: Current and Future Options. Water Science Technology 21(10-11): 1113-1128.

Busby PE, Soman C, Wagner MR, Friesen ML, Kremer J, Bennett A, Dangl JL, 2017. Research priorities for harnessing plant microbiomes in sustainable agriculture. PLoS biology, 15(3), e2001793.

Bünemann EK, Bongiorno G, Bai Z, Creamer RE, De-Deyn G, De-Goede R, Pulleman M, 2018. Soil quality-A critical review. Soil Biology and Biochemistry, 120, 105-125.

Dawood M, Wahid A, Hashmi MZ, Mukhtar S, Malik Z, 2017. Use of earthworms in biomonitoring of soil xenobiotics. In: Hashmi M., Kumar V., Varma A. (eds) Xenobiotics in the Soil Environment. Soil Biology Vol. 49,pp. 73-88.

Dominguez J, Edwards C, 2011. Biology and Ecology of Earthworm Species Used for Vermicomposting. In: Vermiculture Technology (Edited by Clive A. Edwards, Norman Q. Arancon and Rhonda Sherman) Earthworms, Organic Wastes, and Environmental Management, CRC Press, pp. 27-40.

Dunger W, 1983. Tiere im Boden. A. Ziemsen Verlag, Wittenberg Lutherstadt.

Environmental Protection Agency (EPA) Method-3052, 1996. Microwave Assisted Acid Digestion of Siliceous and Organically Based Matrices. https://www.epa.gov/sites/production/files/2015-12/documents/3052.pdf.

Evans AC, 1947. A Method for studying the burrowing activities of earthworms. Annals and Magazine of Natural History, 11: 643-650.

Felten D, Emmerling C, 2009. Earthworm burrowing behaviour in 2D terraria with single-and multi-species assemblages. Biology and Fertility of Soils, 45(8), 789-797.

Fründ HC, Graefe U, Tischer S, 2011. Earthworms as Bioindicators of Soil Quality. In: Karaca A. (ed.) Biology of Earthworms. Soil Biology. Springer Berlin Heidelberg Vol. 24, pp.261-278.

Fründ HC, Wallrabenstein H, Leibner S, Blohm R, 2009. Developing a soil quality test with 2D terraria and Aporrectodea caliginosa. Workshop Kommission III der Deutschen Bodenkundlichen Gesellschaft "Experimenting with Earthworms." Trier, Germany: Veranstalter: Kommission III der DBG 20-21.03.2009. http://eprints.dbges.de/90/2/Fruend.

Fuller H, 1954. Die Regenwürmer. Die Neue Brehm-Bücherei, Heft 140 (Nachdruck). Wittenberg: A. Ziemsen Verlag.

Gallagher FJ, Caplan JS, Krumins JA, Grabosky JC, 2015. Root Growth Responses to Soil Amendment in an Urban Brownfield. Ecological Restoration 33(1) p: 10-13.

Graff 0, 1953. Die Regenwürmer Deutschlands. Hannover. Schaper. 
Gülser C, Kızllkaya R, 2013. Concept of soil quality. A 437 Актуальные проблемы науки и агропромышленного комплекса в процессе европейской интеграции, Международная науч.-практичес, 273.

IOOC (International Olive Oil Council), 2011. http://www.internationaloliveoil.org/(accessed 01.12.11).

İlay R, 2009. Zeytin Katı Atığının Fasulye ve Ayçiçeği Bitkilerinin Gelişimi Üzerine Etkilerinin Saptanması. Yüksek Lisans Tezi, Çanakkale Onsekiz Mart Üniversitesi-FBE, ÇANAKKALE

İlay R, Kavdır Y, Sumer A, 2013. The effect of olive oil solid waste application on soil properties and growth of sunflower (Helianthus annuus L.) and bean (Phaseolus vulgaris L.) International Biodeterioration \& Biodegradation 85: 254259.

Kacar B, Kütük C, 2010. Gübre Analizleri. Nobel Yayın No: 1497, Fen Bilimleri: 102, Bilim ve Araştırma Merkezi Yayın No: 59, Nobel Yayın Dağıtım Ltd. Şti., Ankara.

Karlen DL, Doran JW, Weinhold BJ, Andrews SS, 2003. Soil quality: Humankind's foundation for survival. Journal of Soil and Water Conservation 58.

Kavdır Y, İlay R, 2011. Earthworms and Soil Structure, In: A.Karaca (ed.), Biology of Earthworms, Soil Biology, Vol 24, pp.39-50. Springer-Verlag Berlin Heidelberg.

Kavdır Y, Killi D, 2008. Influence of olive oil solid waste applications on soil pH, electrical conductivity, soil nitrogen transformations, carbon content and aggregate stability. Bioresource Technology 99, 2326-2332.

Kavdır Y, Turhan H, Camcı Çetin S, Kavdır I, Genç L, Killi D, 2010. Zeytin Katı Atığının (Pirina) Toprağa Doğrudan ve Kompost Yapılarak Uygulanmasının, Agregat Stabilizasyonu ve Bitki Gelişimi Üzerine Etkilerinin Belirlenmesi. TUBITAK Proje No: 1060371 sonuç raporu.

Kizllkaya R, Hepsen Turkay FS, Turkmen C, Durmus M, 2012. Vermicompost effects on wheat yield and nutrient contents in soil and plant. Archives of Agronomy and Soil Science, 58(sup1), S175-S179.

Lee KE, 1985. Earthworms, Their ecology and relationships with soils and land use. Academic Press, 411s. Sydney.

Leibner S, Fründ HC, Schacht H, Blohm R, 2008. Standardisierung und Validierung eines Bodenqualitätstests auf Basis der Bodennutzung durch Regenwürmer. - Berichte der DBG, http://www.dbges.de

Lowe CN, Butt KR, Cheynier KY-M, 2016. Assessment of avoidance behaviour by earthworms (Lumbricus rubellus and Octolasion cyaneum) in linear pollution gradients. Ecotoxicology and Environmental Safety 124: 324-328.

Mısırlığlu M, 2014. Toprak Faunası. Nobel Akademik Yayıncılık Eğitim Danışmanlık Tic. Ltd. Şti., Yayın no;929; Fen Bil. No; 082, I.Basım, Haziran-2014, Ankara.

Müftüoğlu NM, Türkmen C, Çıkılı Y, 2014. Toprak ve Bitkide Verimlilik Analizler (2. Basım). Nobel Akademik Yayıncılık Eğitim Danışmanlık Tic. Ltd. Şti., Ankara Dağıtım Kültür Mah. Mithatpaşa Cad. No: 74 B01/02 Kızılay-Ankara,

Niaounakis M, Halvadakis CP, 2004. Olive-mill Waste Management-Literature Review and Patent Survey. TypothitoGeorge Dardanos, Athens.

Özdemir N, Durmuş ÖTK, 2016. Organik düzenleyicilerin asit, nötr ve alkalin toprakların agregat stabilitesi üzerine etkileri. Toprak Bilimi ve Bitki Besleme Dergisi, 4(1), 22-26.

Öztürk İ, Demir İ, Altınbaş M, Arıkan OA, Çiftçi T, Çakmak İ, Öztürk L, Yıldız Ş, Kiriş A, 2010. Kompost el kitabı, İTÜİSTAÇ ortak basımı,

Paoletti MG, Sommaggio D, Favretto MR, Petruzzelli G, Pezzarossa B, Barbafieri M, 1998. Earthworms as useful bioindicators of agroecosystem sustainability in orchards and vineyards with different inputs. Applied Soil Ecology, 10: 137-150.

Roig A, Cayuela ML, Sánchez-Monedero MA, 2006. An overview on olive mill wastes and their valorisation methods. Waste Management, 26(9), pp.960-969.

Sofi JA, Lone AH, Ganie MA, Dar NA, Bhat SA, Mukhtar M, Dar MA, Ramzan S, 2016. Soil microbiological activity and carbon dynamics in the current climate change scenarios: A review. Pedosphere. 26: 577-591.

Stephenson GL, Kaushik A, Kaushik NK, Solomon KR, Steele T, Scroggins R, 1998. Use of an avoidance-response test to assess the toxicity of contaminated soils to earthworms. In: Sheppard, S.C., Bembridge, J.D., Holmstrup, M., Posthuma, L. (Eds.) Advances in Earthworm Ecotoxicology. SETAC Press, Boca Raton, FL, pp. 67-81.

Thompson PB, 2017. The spirit of the soil: Agriculture and environmental ethics. Taylor \& Francis.

Türkmen C, Şahin E, Dardeniz A, Müftüoğlu NM, 2018. Toprağa Karıştııılan Asma Budama Atıkları Kompostu ve Çay Çöpü Kompostunun Eisenia fetida ve Octodrilus transpadanus (Annelida-Clitellata) Topraksolucanı Yönelimlerine Etkisi. Türk Tarım ve Doğa Bilimleri Dergisi, 5(3), 273-279.

Türkmen C, Temel E, Çatal G, Sinecen M, Mısırlıŏlu M, 2013. Bazı Atık ve Toprak Düzenleyicilerin Toprakta Solucan Davranışlarına Etkisi. ÇOMÜ Ziraat Fakültesi Dergisi 1 (1): 79-86.

Zhongjun JIA, Kuzyakov Y, Myrold D, Tiedje J, 2017. Soil Organic Carbon in a Changing World. Pedosphere 27(5), 789791. 